\title{
Measurement of Nonlinearity as a Diagnostic Tool for Quality Determination of Lead-free Solder Joints
}

\author{
Aleš Duraj ${ }^{1)}$, David Bušek ${ }^{1)}$, and Andrej Mlích ${ }^{1)}$ \\ ${ }^{1)}$ Department of Electrotechnology, Faculty of Electrical Engineering \\ Czech Technical University, Prague 6, 166 27, Czech Republic \\ E-mail : duraja@centrum.cz
}

\begin{abstract}
At present there are directions RoHS-WEEE in European Union which restrict the use of certain hazardous substances in new electric and electronic products. Therefore mass usage of leadfree soldering in electronic production started. A typical alloy for lead-free soldering is based on Sn, $\mathrm{Ag}$ and $\mathrm{Cu}(\mathrm{SAC})$. For the most of types of lead-free solders is necessary to use technological process of soldering in reduced oxygen concentration atmosphere for improvement of wettability of soldered surfaces. Quality of these soldered joints is evaluated according of their electrical and mechanical properties. This paper is focused on measurement of nonlinearity, electrical resistance and mechanical strength. Especially evaluation of nonlinearity as a diagnostic tool for the prediction of solder joints reliability has been tested. Also effect of different surface finish of PCBs and influence of reduced oxygen concentration on quality of joints has been examined.
\end{abstract}

\section{INTRODUCTION}

Soldering is extensively used for assemble electronic components to printed circuit boards or chips to substrates in microelectronic devices. Solder joints serve as mechanical, thermal and electrical interconnections, therefore solder point integrity is a key to reliability concern. Eutectic $63 \mathrm{Sn} / 37 \mathrm{~Pb}$ solder, with a melting temperature of $183{ }^{\circ} \mathrm{C}$, is one of the most common solder alloys due to high strength and resistance to creep. Nevertheless in 1998 European Union introduced a draft directive called WEEE (Waste from Electrical and Electronic Equipment) which calls for restriction of use of certain hazardous substances (lead including) in new electric and electronic products. That is why lead-free solders are widely used for a replacement of tin-lead solders.

A number of industry groups and consortiums (EU - BRITE/EURAM, USA - NEMI, Japan JEIDA, etc.) are working in this area to find an optimal solder alloy replacement. A variety of $\mathrm{Sn} / \mathrm{Ag} / \mathrm{Cu}$ (SAC) alloy compositions have been recommended with only a slight difference in actual compound. BRITE/EURAM: 95,5 Sn3,8Ag0,5Cu, NEMI: $95,5 \mathrm{Sn} 3,9 \mathrm{Ag} 0,6 \mathrm{Cu}$ and JEIDA:
$96,5 \mathrm{Sn} 3 \mathrm{Ag} 0,5 \mathrm{Cu}$ recommended these alloys as the best available option for surface mount reflow solder applications. Also systems $\mathrm{Sn} / \mathrm{Ag} / \mathrm{Bi}$ are used in some Japanese products. However, $\mathrm{Sn} / \mathrm{Ag} / \mathrm{Cu}$ systems are more tolerant toward $\mathrm{Pb}$ contamination than $\mathrm{Bi}$ containing systems. Therefore they are more compatible with existing infrastructure for the transition stage. Lead-free surface finishes for PCBs include OSP (Organic Solder Protection), HASL (Hot Air Solder Leveling), electroless $\mathrm{Ni}$ /immersion $\mathrm{Au}$ (ENIG), electroless Ni/electroless Pd, electrolytic Sn, immersion $\mathrm{Sn}$ and etc. These surface finishes have radical effect on quality and reliability of soldered connections. Also some lead-free surface finishes for components exist, such as pure-Sn, Ni/Pd, Ni/Au, Pd etc. Nevertheless many components with $\mathrm{Sn} / \mathrm{Pb}$ surface finish of leads are also still available and contamination by $\mathrm{Pb}$ can occur. Quality of soldered joints is most often evaluated with measuring of resistance, mechanical strength and SEM analysis. Nevertheless linearity of current-voltage characteristics is also a significant parameter for many electronic applications. Therefore this work is focused on utilization of nonlinearity measurement as a tool for quality determination of tin-lead and lead-free solder joints. 


\section{APPLIED MATERIALS AND EXPERIMENTS}

Experiment involves one type of tin-lead solder and two types of lead-free solders. Compound and alloy melting point is shown in Tab.1.

\begin{tabular}{|c|c|}
\hline Solder & Melting point \\
\hline \hline $\mathbf{1}-62 \mathrm{Sn} / 36 \mathrm{~Pb} / 2 \mathrm{Ag}$ & $179^{\circ} \mathrm{C}$ \\
\hline $\mathbf{2}-96,5 \mathrm{Sn} / 3 \mathrm{Ag} / 0,5 \mathrm{Cu}$ & $219^{\circ} \mathrm{C}$ \\
\hline $\mathbf{3}-95,5 \mathrm{Sn} / 4 \mathrm{Ag} / 0,5 \mathrm{Cu}$ & $217^{\circ} \mathrm{C}$ \\
\hline
\end{tabular}

Tab. 1. Solders for experiments

Tested joints have been prepared by assembly of SMD resistors (type 1206 0R0 - Ni/Sn terminations surface finish) on PCBs. Basic material of the testing board is conventional fiberglass laminate (FR4) and material of conductive paths is plated $\mathrm{Cu}$ ( $35 \mu \mathrm{m}$ foil) - shown in Fig. 1. There have been used five types of surface finishes: $\mathrm{FR} 4+\mathrm{Cu}$ (brushed), $\mathrm{FR} 4+\mathrm{Cu}+\mathrm{OMN}$ (Organic Metal Nanofinish), FR4+Cu+HASL $(60 \mathrm{Sn} / 40 \mathrm{~Pb}), \quad \mathrm{FR} 4+\mathrm{Cu}+\mathrm{Immersion} \quad \mathrm{Sn}, \quad \mathrm{FR} 4+\mathrm{Cu}+$ $\mathrm{Ni} / \mathrm{Au}$.

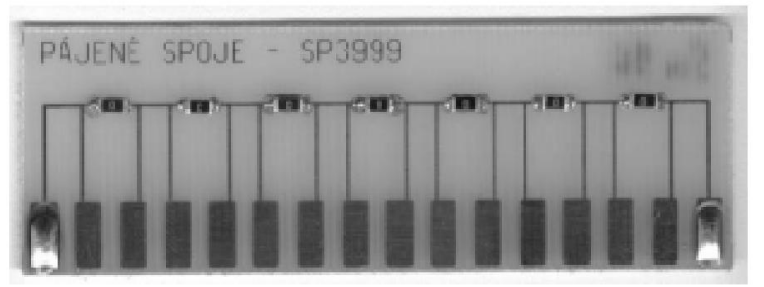

Fig. 1. Assembled testing board

For reflow process of tin-lead and lead-free solders has been used temperature profile of continuous furnace - shown in Fig. 2.

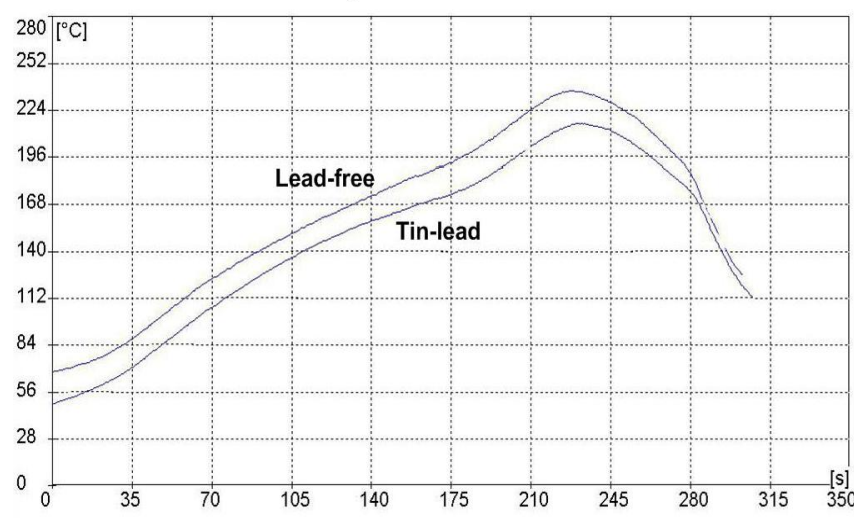

Fig. 2. Reflow profile for tested solders.

There have been prepared two sets of testing samples for both of types of solders (tin-lead and leadfree) depending on reflow conditions: $1^{\text {st }}$ group (A) - reflow soldering process in normal (ambient) atmosphere.

$2^{\text {nd }}$ group (B) - reflow soldering in reduced oxygen concentration atmosphere $\left(\mathrm{N}_{2}, \sim 1 \times 10^{3} \mathrm{ppm} . \mathrm{O}_{2}\right)$.

\section{EXPERIMENTS}

These experiments are mainly focused on evaluation of influence of surface finish of PCB on electrical and mechanical properties of solder joint. Following parameters of the joints have been investigated and compared: electrical resistance and nonlinearity of the current vs. voltage characteristics. Also tensile strength of the soldered joints has been measured. All testing boards have been also strained with dynamic mechanical load (bending) for investigation of reliability of soldered joints under mechanical stress (mechanical fatigue test). For research of structure of metallic layers on component terminations there were used Energy Dispersive Spectrometry (EDS). This analysis is most often used for qualitative elemental study, simply to determine which elements are present and their relative abundance. From this analysis of SMD is evident that surface finish of terminations is $\mathrm{Ni} / \mathrm{Sn}$.

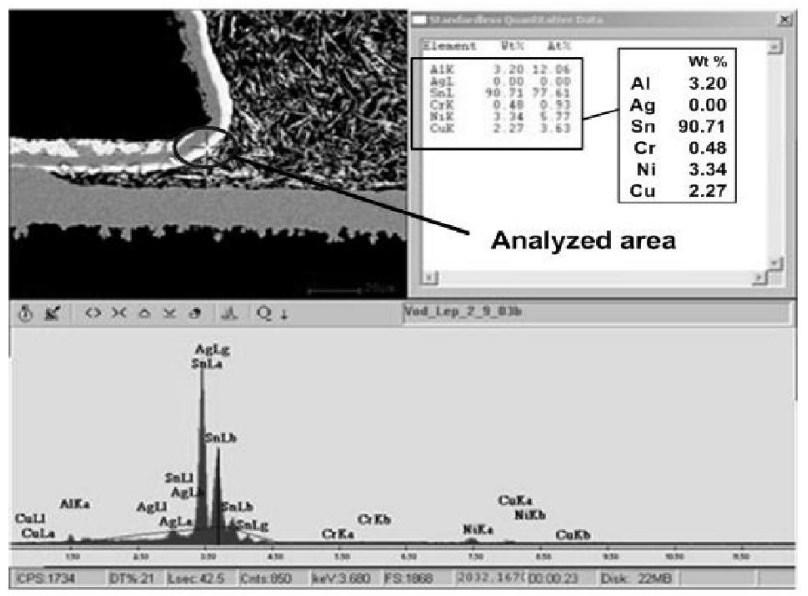

Fig. 3. EDS analysis of the SMD terminations

\subsection{Electrical resistance}

Electrical resistance is mostly measured parameter for its simplicity and high predicative rate for determination of quality of joints. Resistance of the joints has been measured with the precision LCR meter HP 4284A. The samples have been contacted with four-point probe method. Electrical resistance of 
whole testing board Rwb has been measured and evaluated (daisy-chain of 7 SMDs). Results of measurement of electrical resistance Rwb are shown in Tab.2.

\begin{tabular}{|c|c|c|c|c|c|c|}
\hline \multirow{2}{*}{ Rwb [m $\mathbf{\Omega}]$} & \multicolumn{2}{|c|}{} & \multicolumn{2}{|c|}{2} & \multicolumn{2}{|c|}{3} \\
\cline { 2 - 7 } & A & B & A & B & A & B \\
\hline $\mathrm{Cu}$ (brushed) & 84,5 & 82,5 & 79,0 & 78,5 & 75,0 & 78,0 \\
\hline $\mathrm{Cu}+\mathrm{HASL}$ & 86,0 & 87,5 & 75,5 & 77,0 & 77,5 & 78,5 \\
\hline $\mathrm{Cu}+\mathrm{OMN}$ & 81,0 & 82,0 & 78,0 & 76,5 & 77,0 & 76,5 \\
\hline $\mathrm{Cu}+\mathrm{Ni} / \mathrm{Au}$ & 83,0 & 86,5 & 78,5 & 79,5 & 77,5 & 81,5 \\
\hline $\mathrm{Cu}+\mathrm{Sn}$ & 82,5 & 85,0 & 77,0 & 78,0 & 77,0 & 79,0 \\
\hline
\end{tabular}

Tab. 2. Influence of reflow process on electrical resistance Rwb of daisy-chain of soldered SMDs: A - reflow in ambient atmosphere, $\mathrm{B}$ - reflow in inert atmosphere $\left(\mathrm{N}_{2}\right)$

Measurement of electrical resistance is fast and precise method. The highest resistance has been measured for $62 \mathrm{Sn} / 36 \mathrm{~Pb} / 2 \mathrm{Ag}$ solder. Variances in resistance between different surface finishes of PCBs are less than $\pm 5 \%$. In most cases the lowest joint resistance for $\mathrm{OMN}$ surface finish was measured. It is clear that initial solder joint resistance for all tested metallization of PCBs is very similar.

\subsection{Nonlinearity of the C-V characteristics}

Measurement of nonlinearity of the current-voltage characteristics is in electrotechnics sometimes used for quality and reliability prediction [1]. In our case we used the method of evaluation of the intermodulation distortion and it has been evaluated with spectral analyzer unit HP 8560E. Intermodulation is the result of two signals of different frequencies being mixed together, forming additional signals at frequencies that are not in general at harmonic frequencies (integer multiples) of either. In principle, the intermodulation products are described by following equation:

$$
f=n \cdot f_{1}+m \cdot f_{2}
$$

The chosen frequencies: $\mathrm{f}_{1}=4,106 \mathrm{MHz}, \mathrm{n}=1$

$$
\mathrm{f}_{2}=150 \mathrm{kHz}, \mathrm{m}=2
$$

Then measured frequency is $\mathrm{f}=4,406 \mathrm{MHz}$.

In our experiment we used power measurement relative to 1 milliwatt - evaluation of nonlinearity in $\mathrm{dBm}$. For evaluation of third harmonics $\mathrm{U}_{\mathrm{c}}=\mathrm{U}_{3}$ we can use equation (2) or evaluation with nonlinearity index NI (3):

$$
\begin{aligned}
& U_{c}=224 \cdot 1000 \cdot 10^{N I / 20} \quad[\mu V] \\
& N I=20 \cdot \log \frac{U_{c}}{U_{1}} \quad[d B m]
\end{aligned}
$$

Nonlinearity measurements have been performed with equipment designed and constructed at the department of electrotechnology and carried over 2 joints and SMD resistor. Nonlinearity of single resistor is less than $-145 \mathrm{dBm}$ so it is insignificant in evaluations. All analyses are with noise index NI.

\begin{tabular}{|c|c|c|c|}
\hline \multicolumn{4}{|c|}{ A - reflow process in ambient atmosphere } \\
\hline $\mathbf{N I}[\mathbf{d B m}]$ & $\mathbf{1}$ & $\mathbf{2}$ & $\mathbf{3}$ \\
\hline $\mathrm{Cu}$ (brushed) & $-134,9$ & $-135,7$ & $-136,4$ \\
\hline $\mathrm{Cu}+\mathrm{HASL}$ & $-133,4$ & $-135,4$ & $-135,8$ \\
\hline $\mathrm{Cu}+\mathrm{OMN}$ & $-133,0$ & $-135,3$ & $-135,6$ \\
\hline $\mathrm{Cu}+\mathrm{Ni} / \mathrm{Au}$ & $-97,8$ & $-94,9$ & $-91,1$ \\
\hline $\mathrm{Cu}+\mathrm{Sn}$ & $-132,8$ & $-136,2$ & $-136,9$ \\
\hline $\mathrm{B}-$ reflow process in inert $\left(\mathrm{N}_{2}\right)$ atmosphere \\
\hline $\mathbf{N I}[\mathbf{d B m}]$ & $\mathbf{1}$ & $\mathbf{2}$ & $\mathbf{3}$ \\
\hline $\mathrm{Cu}(\mathrm{brushed})$ & $-137,9$ & $-136,9$ & $-137,5$ \\
\hline $\mathrm{Cu}+\mathrm{HASL}$ & $-135,6$ & $-136,9$ & $-136,7$ \\
\hline $\mathrm{Cu}+\mathrm{OMN}$ & $-135,5$ & $-136,5$ & $-137,0$ \\
\hline $\mathrm{Cu}+\mathrm{Ni} / \mathrm{Au}$ & $-78,3$ & $-91,1$ & $-81,6$ \\
\hline $\mathrm{Cu}+\mathrm{Sn}$ & $-135,9$ & $-134,9$ & $-138,1$ \\
\hline $\mathrm{Cu}+\mathrm{Sn}$ & $-135,9$ & $-134,9$ & $-138,1$ \\
\hline
\end{tabular}

Tab. 3. Effect of surface metallization and reflow process on nonlinearity of soldered joints

From the experiment it is evident that nonlinearity measurement as a quality determination tool is not acceptable for all types of surface metallization - see $\mathrm{Tab}$. 3. High nonlinearity for $\mathrm{Cu}+\mathrm{Ni} / \mathrm{Au}$ was measured. Nevertheless this nonlinearity is not caused by failure in connection between SMD and PCB. Boundaries between metallic layers ( $\mathrm{Cu}-\mathrm{Ni}, \mathrm{Ni}-\mathrm{Au})$ on PCB generate nonlinear characteristics for electrical current which passing through. For verification, the measurement of single conduction path on PCB has been carried out. Only $\mathrm{Cu}+\mathrm{Ni} / \mathrm{Au}$ metallization have radical effect on total measured nonlinearity of soldered joints (conductive path: $\mathrm{NI}_{\mathrm{Cu}+\mathrm{Ni} / \mathrm{Au}}=\sim-105 \mathrm{dBm}$ ). For other surface finishes the nonlinearity of conductive paths is insignificant (conductive path: NI $=\sim-145 \mathrm{dBm}$ ). The lowest values of the nonlinearity were measured for clear cooper surface finish ( $\mathrm{Cu}$ brushed) and also for 
immersion Sn metallization. Differences in nonlinearity between solders are less than $\pm 3 \%$. Also difference in nonlinearity between reflow processes for solders in ambient atmosphere and inert atmosphere are less than $\pm 5 \%$.

\subsection{Tensile strength of the joints (Pull-Off test)}

Measurement of tensile strength of joints was conducted with measurement of pull-off force which was led through the PCB (hole $\varnothing 1,8 \mathrm{~mm}$ ) on the underneath of SMD resistor by steel spine. The PCB was fixed in place. Principle of pull-off test (crosssection) is shown in Fig. 4. Results of measurements are shown in Fig. 5. and Fig. 6.

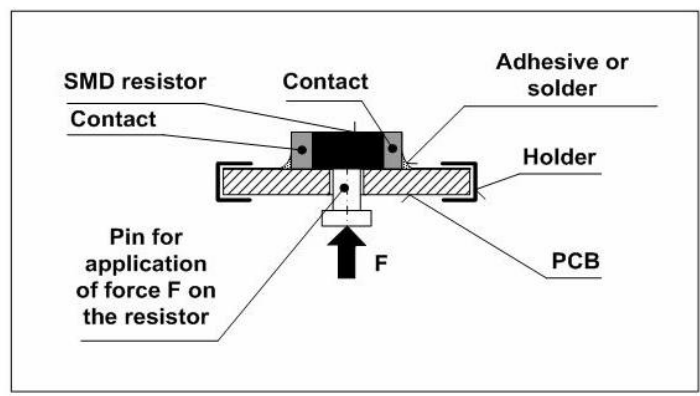

Fig. 4. Tensile strength of the soldered joints - principle of the Pull-off test.
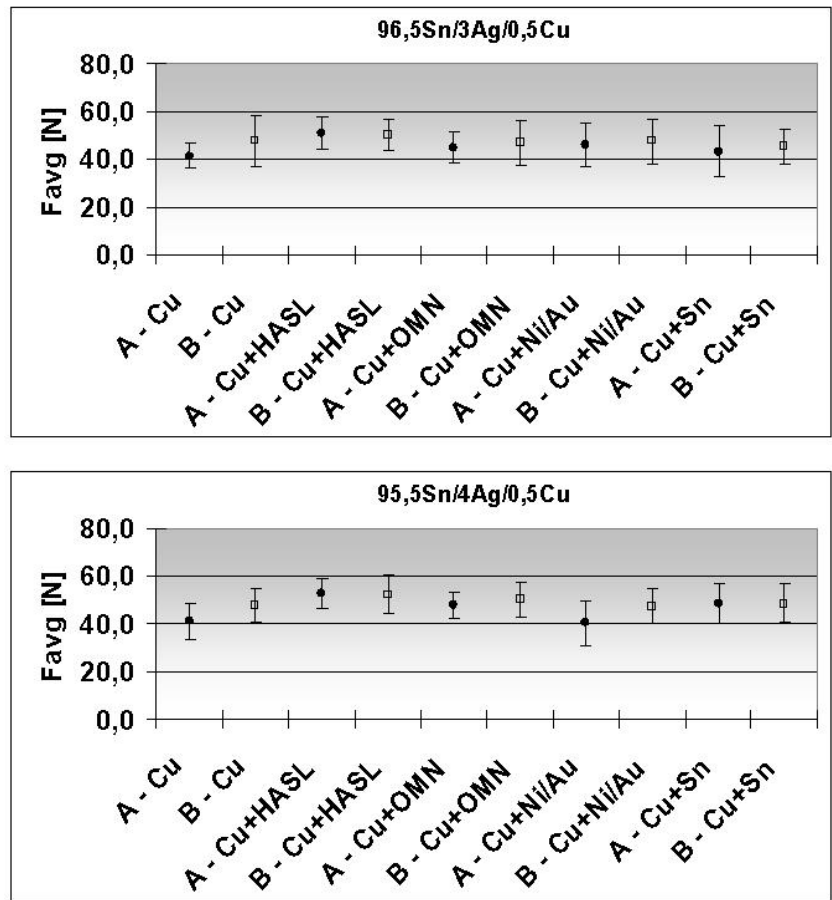

Fig. 5. Pull-off test of lead-free solder joints (SMD 1206)

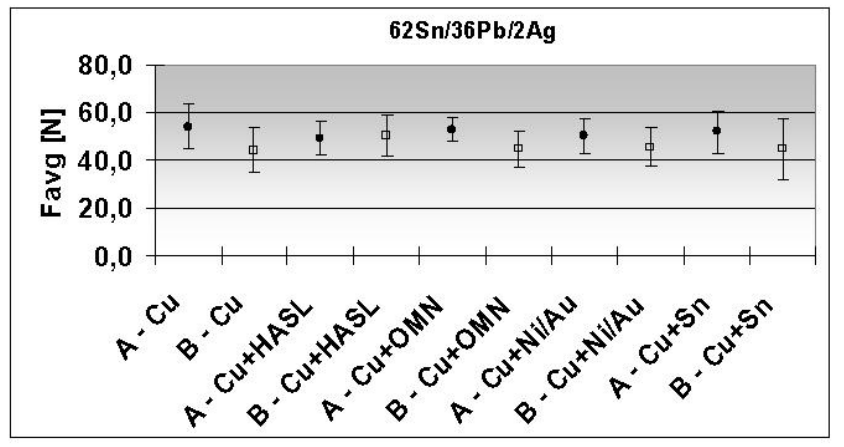

Fig. 6. Pull-off test of tin-lead solder joint (SMD 1206)

Measured force $\mathrm{F}_{\text {avg }}$ which is need for detachment of soldered $1206 \mathrm{SMD}$ has been measured and represents the combination of tensile and shearing strength of joint. Mechanical strengths for two tested lead- free solders are very similar for all types of PCB metallization. A little improvement $(\sim+5 \%)$ of tensile strength was measured for reflow process of lead-free solders in inert atmosphere $\mathrm{N}_{2}$. The highest strength has been found for tested $62 \mathrm{Sn} / 36 \mathrm{~Pb} / 2 \mathrm{Ag}$ solder. Nevertheless inert atmosphere $\mathrm{N}_{2}$ has decreasing effect on measured strength of this solder type.

\subsection{Dynamic mechanical load}

From our experiment it is clear that initial solder joint resistance for all tested metallization of PCBs is very similar. Nevertheless long time stability of resistance and mechanical fatigue of solders mainly depends on the type of solder and also on surface finish of PCBs. Therefore dynamic mechanical load of testing boards has been applied. For application of dynamic mechanical load a special fixture has been realized. The soldered bonds are loaded with different load according to their location on the testing board and its deflection. Schematic principle of the testing is shown on Fig. 7. The more SMD resistors are closer to fixation of board (left side in figure) the more joints are strained with tensile and shear forces.

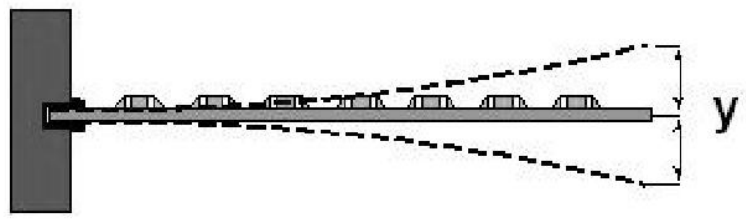

Fig. 7. Principle of dynamic mechanical load

There were choose three values of deflection depending on numbers of cycles of bend for a comparison of influence of dynamic mechanical load 
on joint resistance: $\mathrm{y}= \pm 4,5 \mathrm{~mm}$. After 2000 cycles of straining of testing boards there has been increased deflection to $\mathrm{y}= \pm 6 \mathrm{~mm}$ and applied next 1000 cycles. Because of no radical change in electrical resistance of soldered joints (Rwb - electrical resistance of daisy-chain of 7 SMDs) has occurred, extra high deflection has been set $(\mathrm{y}= \pm 7,5 \mathrm{~mm})$ and next 1000 cycles followed.

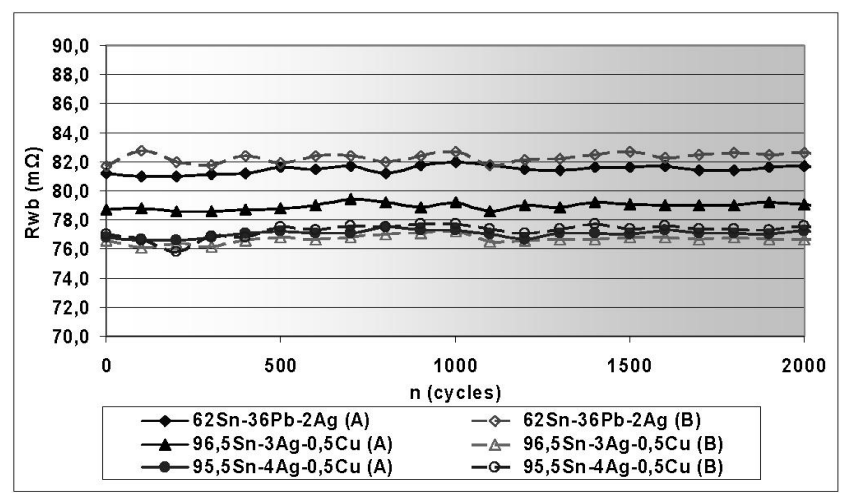

Fig. 8. Effect of dynamic mechanical straining of soldered joints (2000 cycles, $\mathrm{Cu}+\mathrm{OMN}$ PCB metallization).

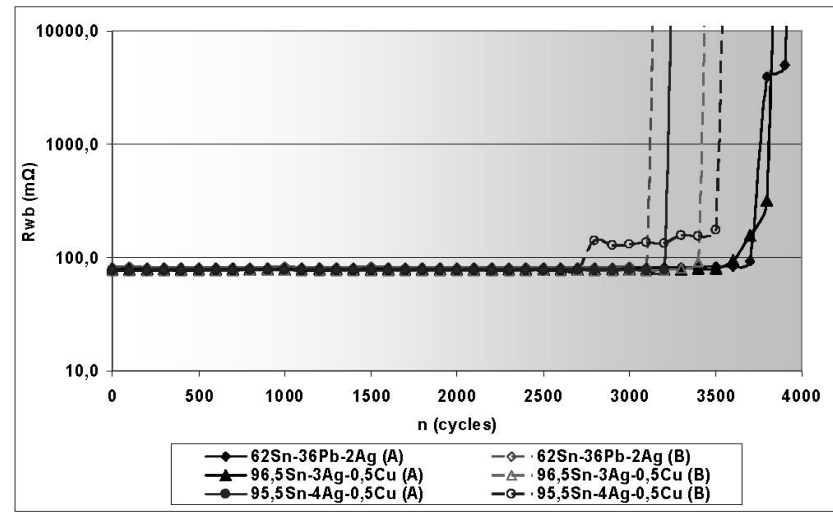

Fig. 9. Evaluation of number of straining cycles for first failure creation in solder joints.

For mechanical straining there were used the same types of solders and substrate FR4 with $\mathrm{Cu}+\mathrm{OMN}$ surface finish. Results of measurement of electrical resistance during mechanical straining ( $\mathrm{y}= \pm 4,5$ $\mathrm{mm}$ ) are shown in Fig. 8. There are no radical differences in resistance of soldered joints for reflow process in ambient atmosphere and inert atmosphere. The first failure in joints occurred for tested tin-lead solder reflowed in an inert atmosphere $\mathrm{N}_{2}$ - see Fig. 9. Also for tested lead-free solders, the reflow process in $\mathrm{N}_{2}$ atmosphere has not radical improving effect on long time stability of electrical resistance. More experiments with different types of surface finish of PCB will continue.

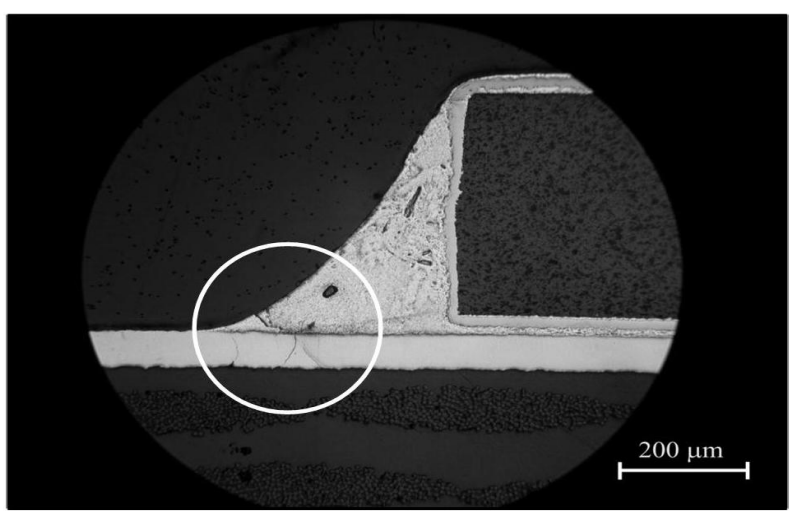

Fig. 10. Failure in soldered joint $(62 \mathrm{Sn} / 36 \mathrm{~Pb} / 2 \mathrm{Ag})$ ( $\mathrm{Cu}+\mathrm{OMN}$ PCB metallization)

\section{CONCLUSIONS}

These experiments evaluate basic electrical and mechanical parameters of soldered joints. Especially evaluation of nonlinearity as a diagnostic tool for quality determination has been tested. Variances in resistance of solders for different surface finishes of PCBs are less than $\pm 5 \%$. Differences in nonlinearity between solders are less than $\pm 3 \%$. Also differences in nonlinearity between reflow processes for solders (ambient atmosphere and inert atmosphere) are less than $\pm 5 \%$. It is evident that measurement of the nonlinearity of the soldered joints has the similar accuracy as the measurement of electrical resistance and can be used for quality establishment.

\section{ACKNOWLEDGMENTS}

This research was supported by grant MSM no. 6840770021 - Diagnostic of Materials, Czech Republic.

\section{REFERENCES}

[1] Duraj, A., Mach, P., "Diagnostic Tools for Evaluation of the Quality of the Anisotropic Conductive Adhesive Joints," in Proc. 29 $9^{\text {th }}$ Int. Spring Sem. Electronics Technology (ISSE'06), St. Marienthal, Germany, May 10-14, 2006, pp. 118-119.

[2] Lau, J.H., Wong, C.P., "Electronics Manufacturing with Lead-Free,Halogen-Free \& Conductive-Adhesive Materials", McGraw-Hill Handbooks, 2003

[3] Vasko, C., Ohera, J., Szeinduch, I., "Investigation of Solder Joints Strength," in Proc. $29^{\text {th }}$ Int. Spring Sem. Electronics Technology (ISSE'06), St. Marienthal, Germany, May 10-14, 2006, pp. 92-93. 